\title{
HIV/AIDS IN EASTERN EUROPE: MORE THAN A SEXUAL HEALTH CRISIS
}

\author{
Jeffrey V. Lazarus ${ }^{1,2}$, Annemarie Bollerup ${ }^{1,3}$, Srdan Matić ${ }^{1}$ \\ ${ }^{1}$ Sexually Transmitted Infections HIVIAIDS Programme, WHO Regional Office for Europe, Copenhagen, Denmark \\ ${ }^{2}$ Division of Social Medicine and Global Health, Lund University, Sweden \\ ${ }^{3}$ Department of Health Sciences, Copenhagen University, Denmark
}

\begin{abstract}
SUMMARY
HIVIAIDS is often described as a sexually transmitted disease. In the former USSR, however, the HIVIAIDS epidemic is being driven by injecting drug use among men. This article addresses several widely circulated assumptions about HIV in eastern Europe: that sexual contact is the primary mode of transmission, that women form a major increasing proportion of those infected, and that the disease threatens young people in particular. Because the rate of injecting drug use is extremely high in many eastern European countries, HIV control there cannot just target sexual transmission but must embrace other approaches, such as comprehensive harm reduction.

In the area of treatment, scaling up access to highly active antiretroviral therapy has been a major global priority for the last two years. European efforts to broaden access have been generally quite successful, yet in the two European countries with the greatest need, the Russian Federation and Ukraine, the demand for treatment is growing much faster than its availability.
\end{abstract}

Key words: epidemiology, HIVIAIDS, harm reduction, antiretroviral treatment, Europe

Address for correspondence: Jeffrey V. Lazarus, STI/HIVIAIDS Programme, WHO Regional Office for Europe, Scherfigsvej 8, DK-2100 Copenhagen Ø, Denmark. E-mail: jla@euro.who.int

\section{INTRODUCTION}

Recently, the global mantra for preventing and treating HIV/AIDS has been to integrate these services with existing reproductive health services, such as antenatal care or sexually transmitted infections clinics. This approach makes good sense in countries with weak health systems where the transmission of HIV is primarily sexual in nature, e.g. sub-Saharan Africa, where HIV preventive measures quite appropriately focus on efforts such as condom promotion $(1,2)$. However, in eastern Europe, where the number of reported HIV cases is increasing more rapidly than in any other region of the world, the situation requires a much different response.

In this article, we examine the nature of HIV transmission in the 15 countries of the former USSR* and the implications for HIV prevention efforts there. As part of our effort to promote an evidence-based response to the epidemic, we also address the assumptions that HIV/AIDS in Europe is primarily transmitted sexually, increasingly "feminised" and a particular problem for young people.

\section{EASTERN EUROPE - THE NEW HIV HOTSPOT}

Worldwide, the majority of new HIV infections are transmitted sexually. However, there exist many pockets of people who have been infected in other ways, e.g. through nosocomial means, contaminated blood supplies, vertical (mother-to-child) transmission and contaminated drug injection equipment. Such modes of transmission are often overlooked in the global perspective (3). While the European Region is making good progress towards eliminating transmission through the first three non-sexual routes, transmission by contaminated needles and other injecting equipment remains a major problem in the former USSR, as discussed below.

In western and central Europe (Table 1), HIV epidemics began in the early and late 1980s, respectively. In western Europe, after a period of relative decline and stability, the rate of newly diagnosed HIV infection is once again increasing, albeit slowly (4). The increase is mainly due to a growing number of cases in heterosexual individuals who come from - and are usually infected in - countries with generalized epidemics (5). However, the number of cases among men who have sex with men has also increased in recent years $(1,5)$. In central Europe, the overall rates of new diagnoses, both for HIV infections and for AIDS, have remained relatively low and stable over the past decade.

By contrast, the HIV epidemic in eastern Europe is still in its early stages, with very few reported cases of HIV until 1994. This changed in early 1995, when the first major outbreaks of HIV were reported among injecting drug users in southern Ukraine (6). Other drug-related HIV outbreaks followed in 1996 in Belarus, in Kaliningrad and other regions of the Russian Federation, and in the Republic of Moldova (7). Since then, the situation in eastern Europe has continued to worsen, and by 1 October 2005, the total

*Listed in Table 1 under "East". 
number of HIV cases reported there had risen to 440,011 of which more than $90 \%$ were in the Russian Federation and Ukraine (8). Moreover, the actual number of people living with HIV/AIDS in the region was estimated to be 1.4 million [range 0.9-2.1 million] by the end of 2004 (9). This rapid increase makes eastern Europe the region of the world with the fastest growing HIV epidemic.

Table 1. The 52 Member States of the WHO European Region

\begin{tabular}{|l|l|l|}
\hline West & Centre & East \\
\hline 1. Andorra & 24. Albania & 38. Armenia \\
2. Austria & 25. Bulgaria & 39. Azerbaijan \\
3. Belgium & 26. Croatia & 40. Belarus \\
4. Denmark & 27. Cyprus & 41. Estonia \\
5. Finland & 28. Czech Republic & 42. Georgia \\
6. France & 29. Hungary & 43. Kazakhstan \\
7. Germany & 30. Malta & 44. Kyrgyzstan \\
8. Greece & 31. Poland & 45. Latvia \\
9. Iceland & 32. Romania & 46. Lithuania \\
10. Ireland & 33. Serbia and & 47. Republic \\
11. Israel & Montenegro & of Moldova \\
12. Italy & 34. Slovakia & 48. Russian \\
13. Lichtenstein & 35. Slovenia & Federation \\
14. Luxembourg & 36. The former & 49. Tajikistan \\
15. Monaco & Yugoslav & 50. Turkmenistan \\
16. Netherlands & Republic & 51. Ukraine \\
17. Norway & of Macedonia & 52. Uzbekistan \\
18. Portugal & 37. Turkey & \\
19. San Marino & & \\
20. Spain & & \\
21. Sweden & & \\
22. Switzerland & & \\
23. United Kingdom & &
\end{tabular}

\section{THREE MYTHS}

\section{Sexual Transmission}

The majority of new HIV infections in eastern Europe occur among injecting drug users. On average, $80 \%$ of the reported cases with a known route of transmission are transmitted through injecting drug use (4). It is true that many of the risk and vulnerability factors for a sexually transmitted HIV epidemic - such as poor knowledge of how HIV is transmitted, low condom use in high-risk populations, a high frequency of other sexually transmitted infections STIs and a flourishing sex industry - are found in many eastern European countries. Nonetheless, sexual transmission rates remain relatively low, and though they are rising, the increases are restricted to a few countries (10). Two examples of such increases are Belarus and Ukraine, where heterosexual transmission accounted for $35 \%$ and $30 \%$, respectively, of all HIV cases reported in 2003, in contrast to $14 \%$ for the entire region (4).

But even in countries where the estimated overall HIV prevalence is greater than $1 \%$, the virus is still concentrated among injecting drug users and their sexual partners, and has not "bridged" into the general population. For example, in a study of risk factors of sexual partners of HIV cases officially registered as infected through sexual contact, from 1996 to 2001 in Odessa, 55-83\% (depending on the year) of the partners were injecting drug users (11). And in St Petersburg, 95\% of all partners of sex workers, regardless of their HIV status, were injecting drug users (12). In addition, transmission attributed to men who have sex with men remains low in the entire eastern European region $(0.2 \%$ of all reported cases in 2003), though there is likely much underreporting due to the extreme stigmatization and risk of incarceration associated with homosexuality in some countries (which is akin to the situation in sub-Saharan Africa).

Therefore, the many reports focusing on sexual transmission as a major driver of the epidemic in eastern Europe $(9,13,14)$ are not only exaggerated but highly misleading.

\section{Feminisation}

Recently, in addressing the HIV/AIDS situation in Latvia, several commentators have argued that young women in the country are particularly vulnerable to HIV infection $(13,14)$, and that "HIV/AIDS is increasingly becoming a female problem" (13). The facts are the following: $27 \%$ of the 3,131 HIV infections reported by May 2005 in Latvia were in women, which does not make the four unfortunate young women described in one article (13) the typical victims. While a woman is biologically more vulnerable to acquiring HIV sexually, there is no convincing evidence that in Latvia she is more likely to become infected than a young adult male, for example, who is in fact more at risk for infection, through injecting drug use. Heterosexual transmission has been identified in only $14 \%$ of all HIV cases (380) in Latvia since the beginning of the epidemic; $81 \%$ of the cases have been due to injecting drug use, mostly among men.

The issue of a feminisation of the epidemic, raised during World AIDS Day 2004 (14), should be considered in the light of the fact that men account for $72 \%$ of the total number of HIV cases reported in eastern Europe since the beginning of the epidemic and $62 \%$ of new HIV infections reported in 2003 (4). Ukraine and the Russian Federation are the only two countries in which women account for a growing proportion of officially reported new HIV diagnoses although the actual number of newly infected women is quite modest (15). In Ukraine, the increase is partly due to improved reporting, notably to increased testing during antenatal care. In the Russian Federation, the increase is partly due to injecting drug use and to sexual contacts with injecting drug users, as mentioned above. Other factors are the reduction in the volume of mandatory testing, owing to Russian budget cuts in the past few years, and an anti-drug law passed in mid-2002 that has intensified the legal prosecution of injecting drug users, which undoubtedly affects the willingness of infected users to report the true mode of transmission. Reduction in the scale of testing and legal restrictions on injecting drug use are both associated with decreased access to testing and counselling among not only drug users but other stigmatized risk groups as well. Given that injecting drug use is much more common among Russian males, the officially reported incidence statistics may not reflect an actual increase in the proportion of females acquiring HIV/AIDS in the Russian Federation (16).

\section{Young People}

"Young people" are increasingly being singled out as the most likely victims of HIV/AIDS in the region, and typically the proportion of cases diagnosed in people below 30 years of age is cited $(9,10,13)$. But according to international standards, including those of the United Nations, the term "young people" is reserved for those aged 10 to 24 . Moreover, $74 \%$ of the total number of 


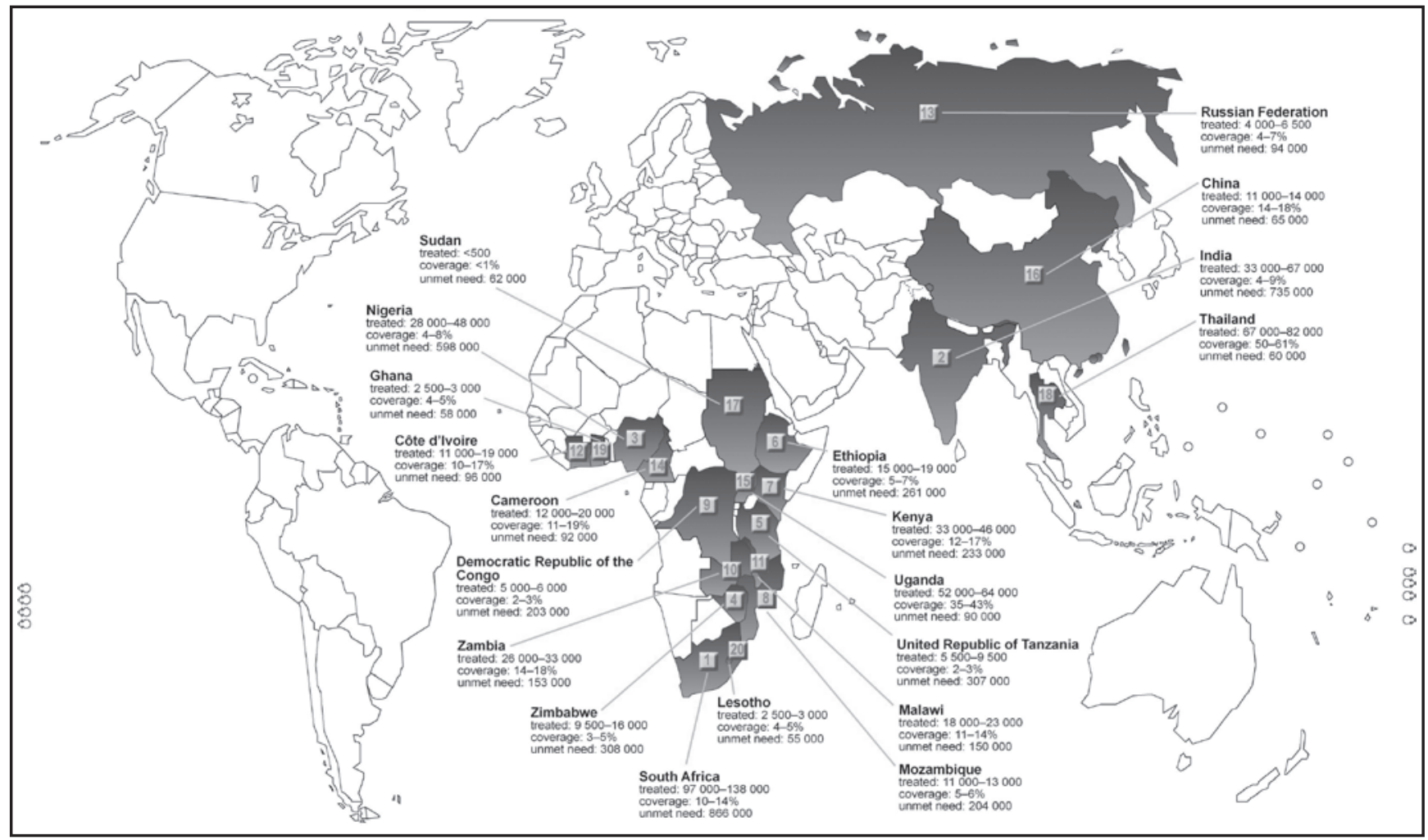

*Unmet need is expressed as the total number of people aged 0-49 in need of antiretroviral treatment in 2005 minus the estimated number of people on treatment in June 2005.

${ }^{* *}$ The figure for the Russian Federation in this map is lower than the new estimates reflected in this article.

HIV cases reported in eastern Europe are people aged 20-39 (4). It is important to distinguish between young people, who are often in school and may still be living at home, and "young adults", who face challenges distinct from those faced by adolescents and youth, such as seeking employment or starting families of their own. Such demographic distinctions are especially critical in designing prevention programmes, since effective interventions for the two groups are substantially different.

\section{BROADENING HIV PREVENTION IN EUROPE}

Because injecting drug use plays such a prominent role in HIV transmission in eastern Europe, and because it is so widespread in many countries there, effective HIV control requires measures well beyond those aimed at reducing sexual transmission. Such initiatives seek to reduce the harm that drug users bring on themselves from drugs or the equipment used to administer them. They include most notably opioid substitution treatment and needle and syringe exchange, both of which have been shown to be an essential part of successful HIV/AIDS prevention and care programmes for injecting drug users (17). While some potential clients for these services may also be in contact with reproductive health-care services, e.g. pregnant injecting drug users, most will not. Clearly, sexual and reproductive health services should refer clients to harm-reduction programmes when relevant. But the feasibility of integrating these harm-reduction services with other HIV/AIDS prevention efforts is currently untenable in eastern Europe, given both the nature of the epidemic there and the resistance to harm-reduction programmes in much of the region.

\section{ACCESS TO ANTIRETROVIRAL TREATMENT IN EUROPE}

In February 2004, the countries of Europe and the former USSR signed the Dublin Declaration on Partnership to Fight HIV/AIDS in Europe and Central Asia, committing themselves to provide universal access to effective, affordable and equitable HIV prevention, treatment and care by 2005 . For WHO, the declaration translated into the concrete goal of providing antiretroviral treatment to an additional 100,000 patients in the region by the end of 2005.

Since January 2003, progress in treatment coverage has been substantial. The number of patients receiving antiretroviral therapy increased from 242,000 to more than 313,000 by October 2005 , and it is expected to have reached 368,500 by the end of 2005. However, treatment gaps are still immense and increasing in many eastern European countries. It is especially true in the two countries with the greatest unmet need, the Russian Federation and Ukraine, where an estimated 139,000 and 17,000, 
respectively, of the 159,000 people in eastern Europe in need of antiretroviral treatment live (Fig. 1). While treatment scale-up has been significant, the need for treatment is growing much faster in these countries than the current rate of scale-up. The present goal of the global treatment scale-up, however, is to make highly active antiretroviral treatment an option for everyone in need. This vision of universal access to prevention, treatment, care and support services by 2010 , whether it be in Europe or in Africa, has now been firmly planted on the world's health and development agendas.

\section{REFERENCES}

1. Robinson AJ, Gazzard BG. Rising rates of HIV infection. BMJ 2005;330(7487):320-1.

2. Liljestrand J, Bryld J, Lazarus JV, Østergaard LR. Synergising HIV/AIDS and sexual and reproductive health and rights - a manual for NGOs. Copenhagen: Aidsnet; 2005.

3. Britton S. The HIV pandemic: darkness prevails but there is light. Scand J Public Health. 2004;32(3):232-3.

4. European Centre for the Epidemiological Monitoring of AIDS (EuroHIV). HIV/AIDS surveillance in Europe: end-year report 2004. No. 71. SaintMaurice: Institute de Veille Sanitaire; 2005.

5. Hamers FF, Downs AM. The changing face of the HIV epidemic in western Europe: what are the implications for public health policies? Lancet. 2004;364(9428):83-94.

6. Hamers FF, Batter B, Downs AM, Alix J, Cazein F, Brunet JB. The HIV epidemic associated with injecting drug use in Europe: geographic and time trends. AIDS. 1997;11(11):1365-74.
7. Dehne KL, Khodakevich L, Hamers FF, Schwartländer B. The HIV/AIDS epidemic in eastern Europe: recent patterns and trends and their implications for policy-making. AIDS.1999;13(7):741-9.

8. Nielsen S, Lazarus JV. HIV/AIDS country profiles for the WHO European Region. In: Matic S, Lazarus JV, Donoghoe M, editors. HIV/AIDS in Europe: moving from death sentence to chronic disease management. Copenhagen: WHO Regional Office for Europe; 2006: 243-74.

9. AIDS epidemic update: special report on HIV prevention. December 2005. Geneva: UNAIDS/WHO; 2005.

10. Hamers FF, Downs AM. HIV in central and eastern Europe. Lancet. 2003;361(9362):1035-46.

11. Risk factors of sexual partners of officially registered HIV cases, infected through sexual contact, 1996-2001. Odessa: Ukraine National AIDS Centre; 2005.

12. Sex work, HIV/AIDS, and human rights in central and eastern Europe and central Asia: a report from the Central and Eastern European Harm Reduction Network. Vilnius: CEEHRN; 2005.

13. Eglitis DS, Cihanovica J. The changing face of AIDS: young Latvian women are four times more likely to get HIV than men are-why? Transitions Online [serial on the Internet]. 2005 May 19 [cited 2005 Oct 10]:1-3. Available from: http://www.tol.cz/look/TOL/article.tpl?IdLanguage $=1 \&$ IdPublication $=4 \&$ NrIssue $=116 \&$ NrSection $=3 \&$ NrArticle $=14045$.

14. World AIDS Day 2004 [homepage on the Internet]. Geneva: UNAIDS [cited 2005 Oct 10]. Available from: http://www.unaids.org.

15. Review of monthly and annual statistical reports. Copenhagen: WHO Regional Office for Europe; 2005. (Unpublished.)

16. Hoppenbrouwer J, Sergeyev B, Nitzsche-Bell A. Assessment of HIV/ AIDS Monitoring and Evalution Practises in the Russian Federation. Moscow: UNAIDS; 2005.

17. Reduction of HIV transmission through drug-dependence treatment [policy brief]. Geneva: WHO; 2004.

Received November 11, 2005 Accepted February 20, 2006 